\title{
Specific Protein Differences Among Strains of Ureaplasma urealyticum as Determined by Two-Dimensional Gel Electrophoresis and a Sensitive Silver Stain
}

\author{
C. E. SWENSON,${ }^{1}+*$ J. VANHAMONT ${ }^{2}$ AND B. S. DUNBAR $\ddagger$ \\ The Population Council, ${ }^{1}$ and Cornell University Medical College, ${ }^{2}$ New York, New York 10021
}

The proteins of nine strains of Ureaplasma urealyticum, representing serovars I through IX, were analyzed by using two-dimensional gel electrophoresis and a sensitive silver staining procedure. The electrophoretic patterns of the nine strains tested could be divided into two distinct major groups, one group consisting of serovars II, IV, V, VII, VIII, and IX (group A) and one group consisting of serovars I, III, and VI (group B).

Ureaplasma urealyticum strains are a serologically heterogeneous group of organisms (16) that are frequently found in human genital tracts. The pathogenic potential of these organisms has been widely disputed, and the significance of their isolation is often unclear $(4,17$, 18). The possibility that some strains or biotypes of $U$. urealyticum are pathogenic and others are not has been suggested (15), but serological differences have not been clearly associated with pathogenicity $(10,15)$. Deoxyribonucleic acid hybridization (5) and one-dimensional (8, 13) and two-dimensional (9) polyacrylamide gel electrophoretic analyses of ${ }^{35}$ S]methionine-labeled proteins have revealed differences among strains of $U$. urealyticum. In two of these studies $(5,9)$, the nine recognized serovars could be separated into two major groups. In this report we describe an additional method of analyzing the proteins of $U$. urealyticum strains by using two-dimensional electrophoresis and a sensitive silver-based stain which combines with proteins in a fashion that produces reproducible and characteristic colors (12). Our findings confirm previous reports of two groups within the species $U$. urealyticum.

Eight strains of $U$. urealyticum originally obtained from F. T. Black, Aarhus, Denmark, and designated serovars I through VIII (3) and one strain obtained from J. A. Robertson, Alberta, Canada, and designated serovar IX (11) were used. These organisms were grown in U-9 broth (14) supplemented with $2 \%$ PPLO serum fraction (Difco Laboratories, Detroit, Mich.) at $37^{\circ} \mathrm{C}$ in an atmosphere containing $5 \% \mathrm{CO}_{2}$. Cultures in the log phase of growth were harvested by

$\dagger$ Present address: Department of Laboratory Medicine, University of California at San Francisco, San Francisco, CA 94143 .

¥ Present address: Department of Cell Biology, Baylor College of Medicine, Houston, TX 77030. centrifugation at $12,000 \times g$ for $1 \mathrm{~h}$ and washed three times with phosphate-buffered saline. The cell pellet obtained from 1 liter of a 20-h culture was sufficient for more than six analyses. Uninoculated medium was incubated and alkalinized to the same degree as growing cultures and was then centrifuged and processed in the same manner. Each strain was grown and tested at least three times.

Each washed cell pellet was suspended in six times its volume of sample buffer containing $2 \%$ sodium dodecyl sulfate, $2 \% \beta$-mercaptoethanol, and $1 \%$ cyclohexylaminoethanesulfonic acid (Calbiochem-Behring Corp., La Jolla, Calif.) (pH 9.5) and heated at $98^{\circ} \mathrm{C}$ for $10 \mathrm{~min}$. Electrophoresis in the first dimension (isoelectric focusing) and the second dimension (sodium dodecyl sulfate slab gel electrophoresis) was performed by using the method of Anderson et al. (2), as described by Dunbar et al. (6). Cylindrical isoelectric focusing gels containing ampholines with a wide $\mathrm{pH}$ range $(\mathrm{pH} 3.5$ to 10 ; LKB, Hicksville, N.Y.) were used. A $20-$ to $40-\mu l$ portion of the solubilized sample was applied to the gels and focussed for $16 \mathrm{~h}$ at $400 \mathrm{~V}$ and $25^{\circ} \mathrm{C}$. After equilibration, the isoelectric focusing gels were applied to 10 to $20 \%$ gradient polyacrylamide gels prepared by using the DALT system (Electronucleonics, Inc., Oak Ridge, Tenn.) described by Anderson et al. (2). This system had the advantage that multiple slab gels could be cast and run simultaneously so that identical gel patterns were easily obtained. In addition, the gradient was easily altered to optimize the resolution of high- or low-molecular-weight proteins. Rat heart homogenate (7) was used for molecular weight standards. After electrophoresis, the gels were fixed and stained by the procedures of Sammons et al. (12). In some cases, a GELCODE silver staining kit (UpJohn Diagnostics, Kalamazoo, Mich.) was used. 


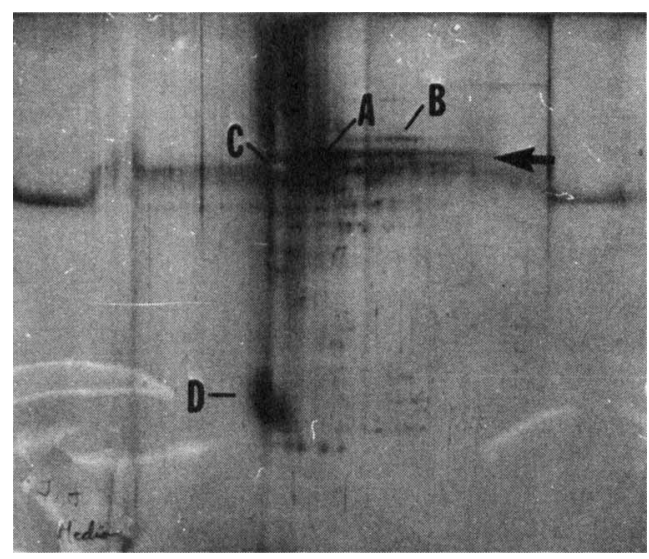

FIG. 1. Two-dimensional gel electrophoresis of uninoculated medium containing PPLO serum fraction: isoelectric focussing in the first dimension followed by sodium dodecyl sulfate-polyacrylamide gel electrophoresis in 10 to $20 \%$ gradient gels in the second dimension. The major medium components are indicated (spots $A$ through $D$ ). The arrow indicates the bands produced by $\beta$-mercaptoethanol.

Figure 1 shows the gel pattern obtained when the solubilized proteins of uninoculated medium were applied to the gel system used. The band running across the upper half of the gel (Fig. 1, arrow) is an artifact due to the presence of mercaptoethanol in the equilibration buffer and occurs at a position corresponding to a molecular weight of 69,000 . The vertical streak on the left (acidic) side of the gel was due to the presence of sodium dodecyl sulfate in the sample. Spot A may represent serum albumin $(1,6$, 12). The chain of spots labeled $B$ stained red, whereas the cluster of spots labeled $C$ stained yellow. The large, diffuse spot at an apparent molecular weight of 22,000 to 26,000 (spot D) stained blue. These components were present in all gels.

The overall patterns obtained with the nine serovars of $U$. urealyticum fell into two general groups; one group consisted of serovars II, IV, V, VII, VIII, and IX (group A), and the other consisted of serovars I, III, and VI (group B). Figure 2 shows representative gels from each group. Numbers were arbitrarily assigned to some of the spots. A number of spots appeared to be common to all strains examined (Table 1). These spots were similar not only in molecular weight and isoelectric point, but also in staining characteristics. For example, spots 14, 31 through 33 , and 35 always stained yellow, and spots 28 and 29 were orange with a surrounding red halo. When the amount of $20 \%$ acrylamide in the gel was increased slightly, the differences between group A and group B strains were readily apparent, and the common cluster of
TABLE 1. Summary of prominent proteins in strains of $U$. urealyticum representing serovars I through IX

\begin{tabular}{|c|c|c|c|}
\hline Group & $\begin{array}{l}\text { Spot } \\
\text { no. }\end{array}$ & $\begin{array}{c}\text { Approx } \\
\text { mol wt } \\
\left(10^{3}\right)\end{array}$ & Color \\
\hline \multirow[t]{9}{*}{ Common $^{a}$} & 1 & 9 & Blue \\
\hline & 7 & 15 & Dark red-purple \\
\hline & 14 & 20 & Yellow \\
\hline & 28 & 32 & Red-orange \\
\hline & 29 & 32 & Red-orange \\
\hline & 31 & 75 & Yellow \\
\hline & 32 & 100 & Yellow \\
\hline & 33 & 100 & Yellow \\
\hline & 35 & 140 & Yellow \\
\hline \multirow[t]{11}{*}{ Group $A^{b}$} & 3 & 12 & Red-orange \\
\hline & 6 & 14.4 & Blue-purple \\
\hline & 9 & 18.5 & Blue \\
\hline & 10 & 19.5 & Blue-orange \\
\hline & 13 & 20 & Red \\
\hline & 15 & 21.5 & Dark blue \\
\hline & 16 & 21.5 & Purple \\
\hline & 17 & 21.5 & Red \\
\hline & 21 & 24.5 & Dark blue \\
\hline & 22 & 24.5 & Purple \\
\hline & 24 & 26 & Maroon-black \\
\hline \multirow[t]{9}{*}{ Group $B^{c}$} & 4 & 12.2 & Red-orange \\
\hline & 5 & 13 & Blue-purple \\
\hline & 8 & 17.5 & Maroon \\
\hline & 11 & 19.5 & Orange \\
\hline & 12 & 20 & Red \\
\hline & 18 & 22 & Red \\
\hline & 19 & 22 & Maroon-black \\
\hline & 20 & 23 & Blue \\
\hline & 23 & 25 & Red \\
\hline \multicolumn{4}{|l|}{ Specific $^{d}$} \\
\hline $\begin{array}{l}\text { II, III, IV, V, } \\
\text { VI, VIII, IX }\end{array}$ & 2 & 10.1 & Blue-purple \\
\hline III, VI & 25 & 28 & Yellow-orange \\
\hline III, VI & 26 & 28 & Yellow-orange \\
\hline II, (IV?) & 27 & 29 & Red-purple \\
\hline IX & 30 & 41 & Red \\
\hline III, V, VI, VIII & 34 & 130 & Yellow \\
\hline
\end{tabular}

${ }^{a}$ Found in all nine serovars.

${ }^{b}$ Found in serovars II, IV, V, VII, VIII, and IX.

${ }^{c}$ Found in serovars I, III, and VI.

${ }^{d}$ Found only in the serovars listed.

proteins labeled 1 formed a consistently unique shape (Fig. 3).

Apparently unique spots were found in some of the strains examined. Serovar IX had a unique polypeptide that stained bright red and had a molecular weight of approximately 41,000 (spot 30) and an isoelectric point similar to that of medium component $D$. This spot was not found in any of the other strains. Spot 27 occurred consistently in the strain representing serovar II and was variable in serovar IV.

The sensitivity of silver-based staining procedures allows the direct examination of proteins from small samples without the need for radiola- 


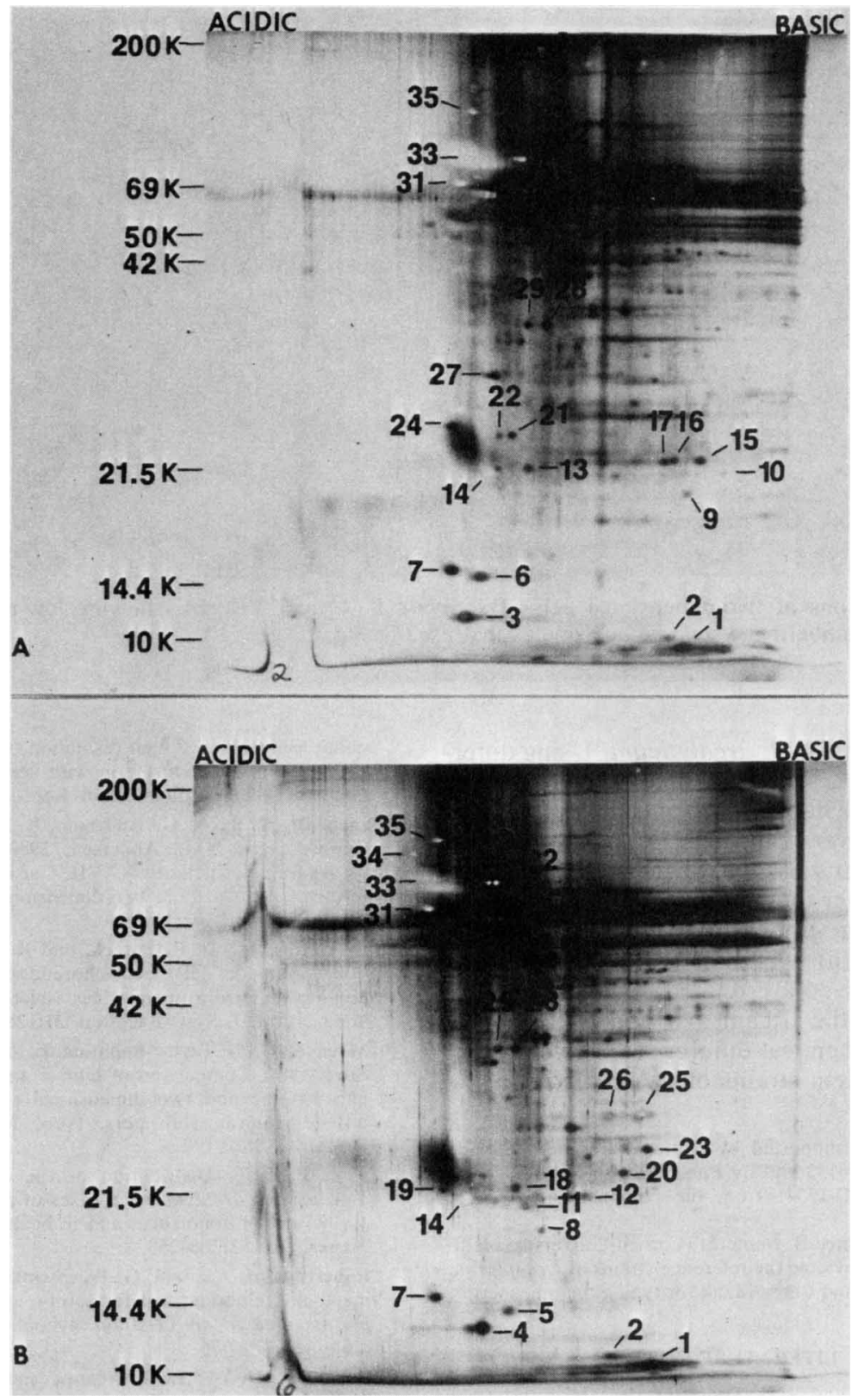

FIG. 2. Two-dimensional gel electrophoresis of two strains of $U$. urealyticum. Some prominent spots are numbered. (A) Serovar II, representing group A strains. (B) Serovar VI, representing group B strains. 200K, Molecular weight of $\mathbf{2 0 0 , 0 0 0}$.

beling. In addition, the staining procedure of Sammons et al. (12) produces protein spots with characteristic colors. This property facilitates visual analysis of gels and provides additional information on the characteristics of the proteins present. It has been suggested that some proteins may have different colors depending on posttranslational modification, amino acid con- tent, the concentration of the protein in the gel, or the type of moiety that is covalently linked to the protein. Although it is not yet understood how the variety of colors are produced, it is clear that color is a unique and reproducible property of the proteins.

Deoxyribonucleic acid hybridization and gel electrophoresis have indicated clear differences 

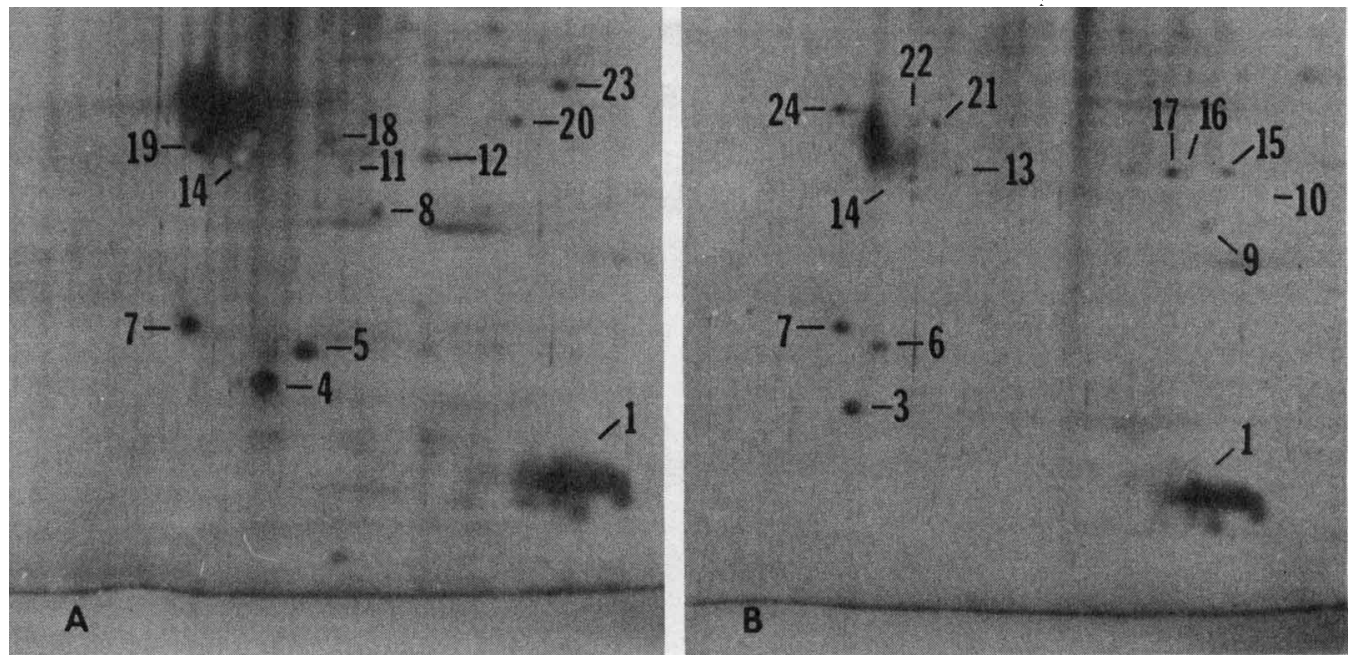

FIG. 3. Sections of two-dimensional gels of serovars I (A) and VII (B), showing low-molecular-weight proteins. The numbering system is the same as that used in Fig. 2.

between strains of $\boldsymbol{U}$. urealyticum. Using different techniques, we were able to confirm the division of nine human Ureaplasma strains (representing serovars I through IX) into two major groups. Further work will be necessary to determine (i) whether there are more than two major electrophoretic groups within the species $U$. urealyticum, (ii) whether the electrophoretic patterns observed are related to the serological properties of the organisms, and (iii) whether there are biochemical differences between virulent and avirulent strains of $U$. urealyticum.

This work was supported by National Research Service Award 1-F32-HD06132 and by Public Health Service grants HD-15113 and HD-13541 from the National Institutes of Health.

We thank Laurence B. Senterfit (Cornell University Medical College) for providing the reference strains of Ureaplasma used in this work and Larry Mauk for typing the manuscript.

\section{LITERATURE CITED}

1. Anderson, L., and N. G. Anderson. 1977. High resolution two-dimensional electrophoresis of human plasma proteins. Proc. Natl. Acad. Sci. U.S.A. 74:5421-5425.

2. Anderson, N. G., N. L. Anderson, and S. L. Tollaksen. 1979. Operation of the ISO-DALT system. Publication ANLBIM 79-2. Argonne National Laboratories, Argonne, IIl.

3. Black, F. T. 1973. Modification of the growth inhibition test and its application to human T-mycoplasmas. Appl. Microbiol. 25:528-533.

4. Cassell, G. H., and B. C. Cole. 1981. Mycoplasmas as agents of human disease. N. Engl. J. Med. 304:80-89.

5. Christiansen, C., F. T. Black, and E. A. Freundt. 1981. Hybridization experiments with deoxyribonucleic acid from Ureaplasma urealyticum serovars I to VIII. Int. J. Syst. Bacteriol. 31:259-262.

6. Dunbar, B. S., C. Liu, and D. W. Sammons. 1981. Identification of the three major proteins of porcine and rabbit zonae pellucidae by high resolution two dimensional gel electrophoresis: comparison with serum, follicular fluid and ovarian cell proteins. Biol. Reprod. 24:1111-1124.

7. Giometti, C. S., N. G. Anderson, S. L. Tollaksen, J. J. Edwards, and N. L. Anderson. 1980. Analytical techniques for cell fractions. XXVII. Use of heart proteins as reference standards in two-dimensional electrophoresis. Anal. Biochem. 102:47-58.

8. Howard, C. J., D. H. Pocock, and R. N. Gourlay. 1981. Polyacrylamide gel electrophoretic comparison of the polypeptides from ureaplasmas isolated from cattle and humans. Int. J. Syst. Bacteriol. 31:128-130.

9. Mouches, C., D. Taylor-Robinson, L. Stipkovits, and J. M. Bove. 1981. Comparison of human and animal ureaplasmas by one and two dimensional protein analysis on polyacrylamide slab gels. Ann. Microbiol. (Paris) B132:171-196.

10. Piot, P. 1976. Distribution of the eight serotypes of Ureaplasma urealyticum in cases of nongonococcal urethritis and of gonorrhea, and in healthy persons. Br. J. Vener. Dis. 52:266-268.

11. Robertson, J. A., and G. W. Stemike. 1979. Modified metabolic inhibition test for serotyping strains of Ureaplasma urealyticum (T-strain mycoplasma). J. Clin. Microbiol. 9:773-776.

12. Sammons, D. W., L. D. Adams, and E. E. Nishizawa. 1981. Ultrasensitive silver based color staining of polypeptides in polyacrylamide gels. Electrophoresis 2:135141.

13. Sayed, I. A., and G. E. Kenny. 1980. Comparison of the proteins and polypeptides of the eight serotypes of Ureaplasma urealyticum by isoelectric focusing and sodium dodecyl sulfate-polyacrylamide gel electrophoresis. Int. J. Syst. Bacteriol. 30:33-41.

14. Shepard, M. C., and C. D. Lunceford. 1970. Urease color test medium U-9 for the detection and identification of "T"' mycoplasmas in clinical material. Appl. Microbiol. 20:539-543.

15. Shepard, M. C., and C. D. Lunceford. 1978. Serological typing of Ureaplasma urealyticum isolates from urethritis patients by an agar growth inhibition method. J. Clin. Microbiol. 8:566-574.

16. Shepard, M. C., C. D. Lunceford, D. K. Ford, R. H. 
Purcell, D. Taylor-Robinson, S. Razin, and F. T. Black. 1974. Ureaplasma urealyticum gen. nov., sp. nov.: proposed nomenclature for the human $\mathrm{T}$ (T-strain) mycoplasmas. Int. J. Syst. Bacteriol. 24:160-171.

17. Taylor-Robinson, D., and W. M. McCormack. 1980. The genital mycoplasmas (first of two parts). N. Engl. J. Med. 302:1003-1010.

18. Taylor-Robinson, D., and W. M. McCormack. 1980. The genital mycoplasmas (second of two parts). N. Engl. J. Med. 302:1063-1067. 